\title{
Protection from extinction provided by a conditioned inhibitor
}

\author{
Bridget L. McConnell and Ralph R. Miller \\ State University of New York, Binghamton, New York
}

\begin{abstract}
Three conditioned suppression experiments with rats as subjects investigated the influence of higher order associations in determining the response potential of a target stimulus. In these experiments, a Pavlovian conditioned inhibitor was compounded with the target cue during extinction treatment. In Experiment 1, strong suppression was observed to the target cue that was given extinction treatment in the presence of a conditioned inhibitor, relative to a target that was extinguished with an associatively neutral cue or was extinguished alone, suggestive of enhanced protection from extinction provided by a conditioned inhibitor. This effect was replicated in a sensory preconditioning preparation in Experiment 2; in Experiment 3, in a sensory preconditioning preparation, this protection effect was retroactively attenuated when the conditioned excitor used to train the conditioned inhibitor was extinguished following extinction of the target. This provides evidence that, at least in a sensory preconditioning preparation, stimuli that are only indirectly associated with the target cue can contribute to the response potential of that target.
\end{abstract}

Presentation of an established excitatory conditioned stimulus (CS; e.g., a tone) in the absence of the unconditioned stimulus (US; e.g., a footshock) has long been known to result in a weakened conditioned response (CR) to the CS (Pavlov, 1927). For example, the freezing response that a rat normally exhibits when exposed to a tone that was paired with a footshock decreases as a result of the tone being presented many times without the footshock, a phenomenon called extinction. The conventional extinction treatment involves presenting the target CS alone in the absence of the US and any other stimulus. However, in an effort to illuminate the mechanisms underlying extinction, a number of studies have investigated the effect of extinguishing the target CS in the presence of another cue (e.g., Lovibond, Davis, \& O'Flaherty, 2000; Pearce \& Wilson, 1991; Pineño, 2007; Rescorla, 2000, 2003, 2006; Soltysik, Wolfe, Nicholas, Wilson, \& Garcia-Sanchez, 1983; Thomas \& Ayres, 2004). A consistent finding of such compound extinction is the so-called protection-from-extinction effect, in which nonreinforced presentations of the target CS in compound with a conditioned inhibitor result in relatively little loss of behavioral control by the target stimulus (e.g., Rescorla, 2003; Soltysik et al., 1983).

Theories that speak to learning during extinction often assert that an unfulfilled outcome expectation drives the inhibitory learning (or unlearning [Rescorla \& Wagner, 1972]) that supports extinction (e.g., Bouton, 2004; Larrauri \& Schmajuk, 2008; Wagner, 1981). According to these theories, inhibitory learning should be directly related to the extent to which US expectations exceed the magnitude of the experienced US. Thus, during extinction, presentation of the CS evokes some expectation of the US, which is violated because the magnitude of the experienced US is null. Furthermore, these theories specify that US expectation is based on the information provided by all stimuli that are present during an extinction trial. These theories successfully anticipated the protection from extinction provided by a conditioned inhibitor. Specifically, presenting a conditioned inhibitor during nonreinforced trials serves to reduce the US expectation and, consequently, the inhibitory learning (or unlearning) that supports extinction.

In contrast to the total error reduction accounts of extinction, the extended comparator hypothesis $(\mathrm{ECH}$; Denniston, Savastano, \& Miller, 2001; see also the mathematical implementation of the ECH, Stout \& Miller, 2007) suggests that the protection-from-extinction effect arises from higher order associations (i.e., associations other than that between the target CS and the US). According to the $\mathrm{ECH}$, behavioral control by any given CS is a function of the extent to which the US representation is directly activated by the target CS, relative to the extent to which the US representation is activated by other cues that are themselves associated with the target CS. These other cues are called comparator stimuli, and they can be either punctuate cues or contextual cues. The response potential of the target CS is directly related to the strength of the target CS-US association and inversely related to the product of the target CS-comparator stimulus association and the comparator stimulus-US association. Behavior indicative of inhibition is assumed to arise 
when the product of the target CS-comparator stimulus association and comparator stimulus-US association is strong relative to the target CS-US association. Thus, excitatory responding to a target CS increases (and behavior indicative of inhibition decreases) with increases in the magnitude of the US representation directly activated by the target CS, and excitatory responding to the CS decreases (and behavior indicative of inhibition increases) with increases in the magnitude of the US representation activated through a target-comparator stimulus and comparator stimulus-US associative chain. The interaction of these associative structures is depicted in Figure 1. Link 1 (the target CS-US direct association) is down modulated by the product of Link 2 (the target CS-comparator stimulus association) and Link 3 (the comparator stimulus-US association). The association between the target CS and its comparator stimulus (Link 2) and the association between the comparator stimulus and the US (Link 3) are also modulated by their own comparator processes, which include stimuli that are associated with the comparator stimuli but need not share a within-compound association with the target CS. These stimuli are called secondorder comparator stimuli. The second-order comparator stimuli modulate the effectiveness with which the firstorder comparator stimuli can down-modulate behavioral control by the target CS. Thus, the response potential of the target CS is inversely related to the strength of the first-order comparators and directly related to the strength of the second-order comparators.

In this framework, the ECH accounts for simple Pavlovian extinction as both a weakening of the target X-US association (Link 1) and, if extinction treatment occurs in the acquisition context, a strengthening of the $\mathrm{X}$-context association (Link 2). The protection-from-extinction effect is explained through the combination of generalization decrement and higher order comparator effects. Generalization decrement refers to a decrease in performance when training occurs with a compound but, subsequently, only one of the elements of the compound is presented. In a protection-from-extinction situation, generalization decrement occurs because extinction training is given to the target CS (X) in compound with another cue (e.g., B) but testing occurs on $\mathrm{X}$ alone. This should result in an increase in responding to the target at test (i.e., a decrease in extinction behavior learned to the compound), relative to that which would have been seen if extinction had occurred to X alone or testing had occurred on both elements of the extinction compound. According to the $\mathrm{ECH}$, there are two possible sources of generalization decrement; these include a failure to generalize from the compound

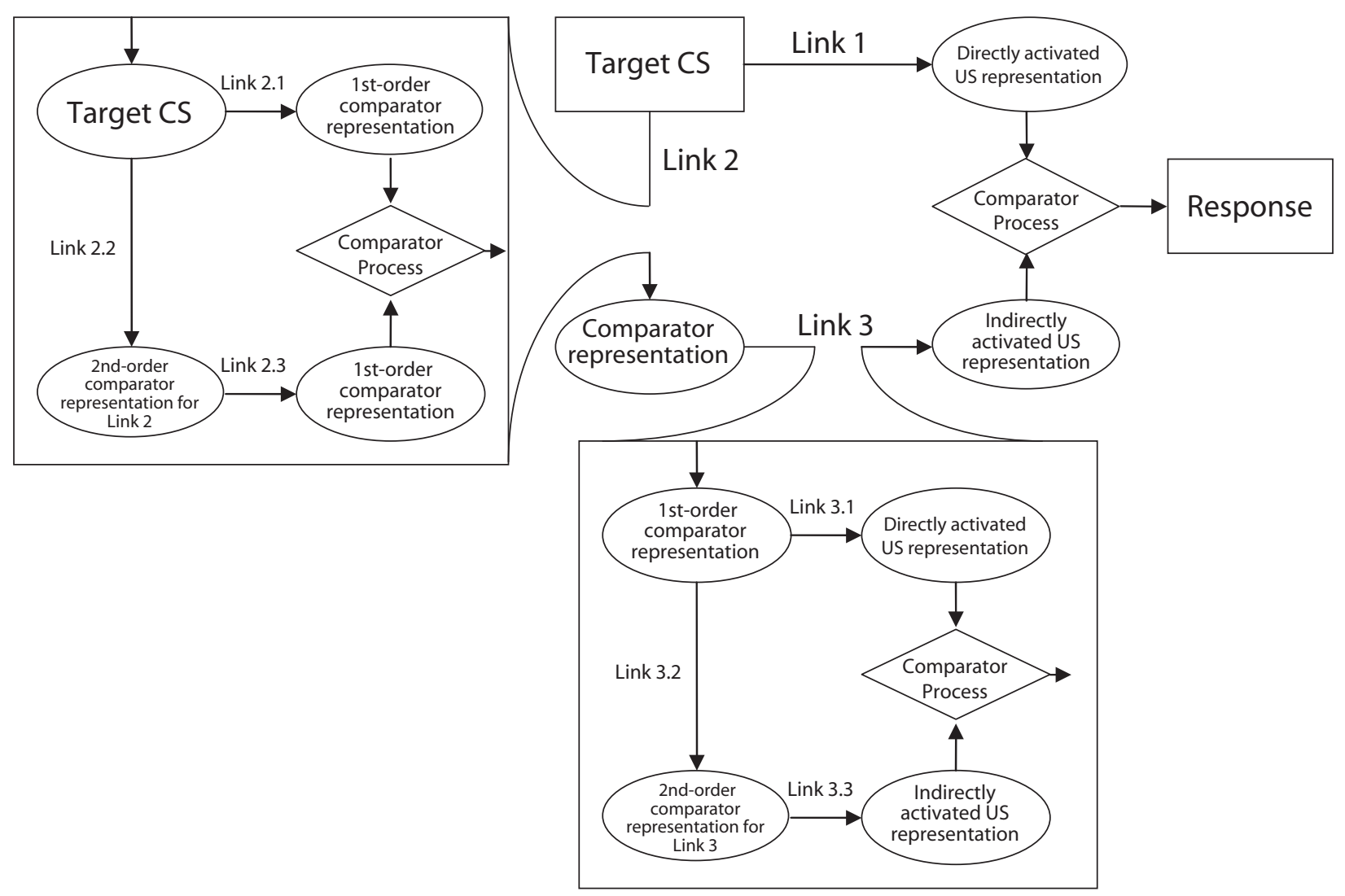

Figure 1. The extended comparator hypothesis (ECH; Denniston, Savastano, \& Miller, 2001). Arrows represent the associations between stimuli. The strengths of the directly and indirectly associated outcome representations are compared in order to determine the strength of responding to the target cue. Ovals depict stimulus representations; rectangles depict physical events; diamonds represent the comparator process. CS, conditioned stimulus; US, unconditioned stimulus. 
of extinction to the element tested and overshadowing by the added element of the target-extinction context association. The ECH does not specify a mechanism for the first source, although it does acknowledge its influence. In the present experiments, to attenuate generalization decrement, individual presentations of the elements that made up the extinction compound (e.g., $\mathrm{X}$ and B) were given interspersed with the compound extinction trials (e.g., XB). This was done to encourage elemental processing of the components of the compound, which, in turn, should facilitate generalization between the compound and the test stimulus. A similar method was used by Rescorla (2000, 2006) for the same purpose. We attempted to attenuate the second source by widely spacing the acquisition and extinction trials in order to minimize formation of any associations to the context. Efforts were taken to reduce generalization decrement in order that the focus of this series of experiments could be on the impact of the nontarget cue present during extinction being inhibitory, rather than on protection from extinction provided by generalization decrement.

According to the $\mathrm{ECH}$, another source of the protectionfrom-extinction effect (and the focus of this series of experiments) is higher order comparator effects in which the Pavlovian conditioned inhibitor (B; established through A-US/AB - training), which is paired with the target CS (X) during extinction treatment, becomes a first-order comparator to $\mathrm{X}$, but its ability to reduce responding to $\mathrm{X}$ is modulated by the excitor $(\mathrm{A})$ that was used to train the conditioned inhibitor. Thus, B is a first-order comparator stimulus for $\mathrm{X}$, and $\mathrm{A}$ is a second-order comparator stimulus for X. Recall that responding to the target CS is inversely related to the strength of the first-order comparator stimulus-US association and directly related to the strength of the second-order comparator stimulus-US association. In this situation, the $\mathrm{X}-\mathrm{B}$ association (Link 2) attenuates responding to $\mathrm{X}$, and the $\mathrm{B}-\mathrm{A}, \mathrm{A}-\mathrm{US}$ associations (Links 3.2 and 3.3) decrease the influence of $\mathrm{B}$ on $\mathrm{X}$ (thereby eliminating the decremental effect of $\mathrm{B}$ on responding to $\mathrm{X}$ ).

In the process just described, the $\mathrm{B}-\mathrm{A}, \mathrm{A}-\mathrm{US}$ associations undermine the influence of the $\mathrm{X}-\mathrm{B}$ association, negating the decremental influence of $\mathrm{B}$. Moreover, the $\mathrm{B}-\mathrm{A}, \mathrm{A}-\mathrm{US}$ associations actively promote responding to X. This occurs because within the higher order comparator process for Link 3 (i.e., Links 3.1, 3.2, and 3.3), the comparator mechanism should yield a negative output for the effective Link 3 (the strength of the output of the higher order comparator process contrasting Link 3.1 with the product of Links 3.2 and 3.3). This output is negative because the conditioned inhibitor (B) is not directly associated with the US (i.e., it was present only when A was not reinforced), which should give Link 3.1 negligible strength, but Links 3.2 and 3.3 should be strong because $\mathrm{A}$ and $\mathrm{B}$ are strongly associated together and $\mathrm{A}$ is strongly associated with the US. Consequently, the second-order comparator process should result in a negative output for the Link 3 comparison (see Stout \& Miller, 2007). Within the first-order comparator mechanism, the negative po- tential of Link 3, in turn, should result in enhanced excitatory conditioned responding to the target CS, relative to extinction in the absence of a conditioned inhibitor, which should not benefit from the negative output of the effective Link 3 (see Figure 2). In other words, the presence of a conditioned inhibitor during extinction should further augment excitatory responding to the target at test through the negative output produced by the Link 3 higher order comparator mechanism.

The ECH emphasizes the interaction between stimuli at the time of testing rather than at the time of training, which is commonly the focus of many acquisition-focused models of Pavlovian conditioning (e.g., Mackintosh, 1975; Rescorla \& Wagner, 1972; Wagner, 1981). In other words, the comparator process takes into account the current value of the comparator stimuli at test, not simply the associative strength that the stimuli had at the time of training. As such, the ECH predicts that changes in the associative strength of comparator stimuli (first or second), even after the target CS has been trained, should affect responding to the target stimulus. Thus, the ECH predicts that the protection-from-extinction effect should be attenuated (i.e., responding to $\mathrm{X}$ should decrease) if $\mathrm{A}$ is extinguished following BX extinction treatment because this removes the negative output by the second-order comparator process.

Experiments 1 and 2, in a conditioned suppression preparation, were designed to replicate the protectionfrom-extinction effect and also to assess the presence of generalization decrement, which was done by investigating the effectiveness of a neutral stimulus $(\mathrm{C})$ in protecting the target from extinction. Under normal circumstances, generalization decrement going from extinction treatment with $\mathrm{CX}$ to testing on $\mathrm{X}$ would be expected to provide $\mathrm{X}$ with a degree of protection from extinction. Recent data from our laboratory (Laborda, Witnauer, \& Miller, 2009; Urcelay, Lipatova, \& Miller, 2009) suggest that extinction in the presence of a neutral stimulus is less effective than extinction in the absence of a neutral stimulus, presumably due to generalization decrement between acquisition and extinction, as well as between extinction and testing. Notably, in the present experiments, generalization decrement was expected to occur whenever another stimulus is present during extinction, regardless of its associative value. Thus, any generalization decrement that occurs should be evidenced when the additional stimulus is neutral and when it is inhibitory.

A previous report by Rescorla (2003) already suggested that a neutral stimulus is less effective than a conditioned inhibitor in protecting an excitor from extinction. Both the $\mathrm{ECH}$ and conventional error reduction models anticipate this effect, but ECH offers a different account of it. According to the $\mathrm{ECH}$, both a conditioned inhibitor and a neutral stimulus should overshadow the $\mathrm{X}$-context association (Link 2) that normally contributes to extinction when extinction treatment occurs in an excitatory context, such as that used for acquisition. This should allow the nontarget stimulus (B or C) to assume the role of a first-order comparator stimulus that decreases behavioral control by 


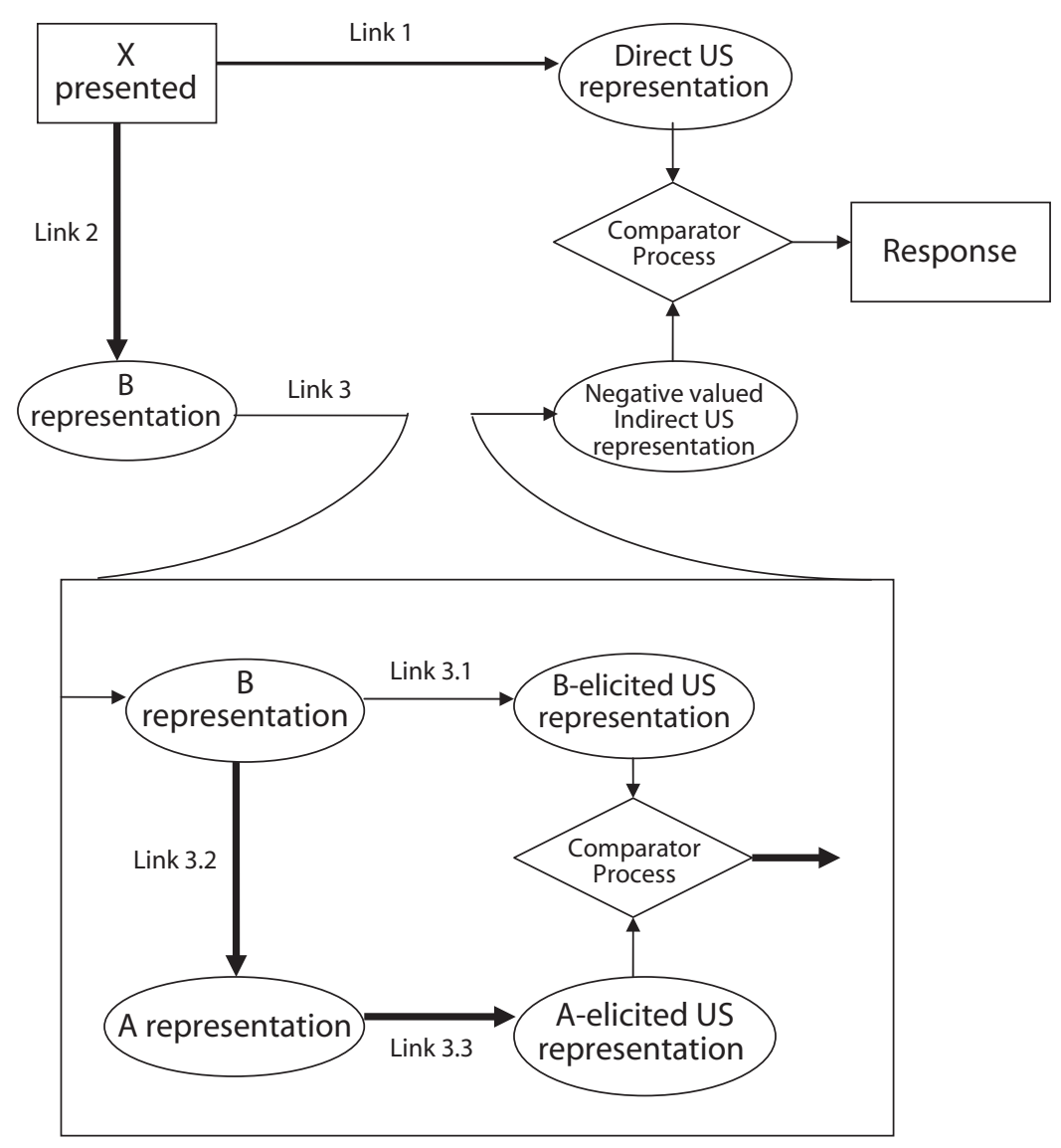

Figure 2. The extended comparator hypothesis account of the protection from extinction provided by a conditioned inhibitor. $X$ is the target cue, $B$ is the Pavlovian conditioned inhibitor, and $A$ is the excitor used to train the conditioned inhibitor. Heavy lines indicate strong associations. US, unconditioned stimulus.

the target CS, which, in turn, should reduce the amount of responding observed. The presence of these stimuli during extinction should also produce generalization decrement when testing occurs on $\mathrm{X}$ alone, which should result in at least a partial protection-from-extinction effect. Moreover, a conditioned inhibitor should actively promote subsequent responding to the target $\mathrm{CS}$ when $\mathrm{X}$ is presented alone, as a result of the target's indirect association with the excitor (A) used to train the conditioned inhibitor (which should result in negative output for Link 3). In contrast, a neutral stimulus does not have a direct or indirect association with the US (which means that Link 3 should have neither a strong excitatory value nor a negative value to compare with Link 1), which should make the effect of its presence negligible, thereby precluding the neutral stimulus from having a stronger influence on responding than does a conditioned inhibitor.

As was stated earlier, in the present experiments, we wanted to focus only on the effect of the associative status of the compounded stimulus. Thus, we gave nonreinforced presentations of $\mathrm{B}$ and $\mathrm{X}$ elementally interspersed with the compound (BX or $\mathrm{CX}$ ) during extinction to bias the subjects to process the stimuli elementally. We also widely spaced the acquisition and extinction trials to minimize associations being formed to the context, which otherwise would cause both the context and the added stimulus to be first-order comparator stimuli, thereby greatly complicating interpretation. Assuming that the role of the context and the influence of generalization decrement are minimal, according to the ECH, extinction of the target $\mathrm{CS}$ in the presence of a neutral stimulus should be as effective as extinction of the target stimulus alone. Although total error reduction models offer another account of protection from extinction provided by extinction treatment in the presence of a conditioned inhibitor, which will be discussed in detail later, the $\mathrm{ECH}$ is unique in predicting that extinction of the excitor used to train the inhibitor should decrease responding to $\mathrm{X}$. Experiment 3 investigated this prediction of the ECH also in a conditioned suppression preparation.

\section{EXPERIMENT 1}

In Experiment 1, we extinguished one group of rats to the target cue $(\mathrm{X})$ in compound with a Pavlovian conditioned inhibitor (Group Inhib). Although conditioned inhibition was not directly assessed in the present series of experiments, the parameters used here were based on 
many explicit demonstrations of conditioned inhibition (i.e., summation and retardation tests) in our laboratory, using the same preparation (e.g., Friedman, Blaisdell, Escobar, \& Miller, 1998). On the basis of the predictions of the ECH and previous demonstrations of the protectionfrom-extinction effect, we expected to see strong conditioned suppression to the target cue. This behavior was compared with that of a group that received extinction to $X$ in compound with a neutral stimulus (Group Neutral), a group that received extinction to X elementally (Group Ext), and a group given no extinction treatment (Group NoExt). We anticipated that the subjects in Group Neutral would exhibit low suppression due to the measures we took to attenuate generalization decrement, which otherwise would have provided partial protection from extinction. Moreover, this group's suppression was expected to be weaker than that in Group Inhib, in which we expected the conditioned inhibitor to increase responding to the target CS. Subjects in Group Ext were expected to show the least suppression, and subjects in Group NoExt were expected to show the highest level of suppression (see Table 1 for the experimental design). Two different contexts were used in order to allow testing in a context that was associatively equivalent for all groups.

\section{Method}

\section{Subjects}

The subjects were 24 male and 24 female, experimentally naive Sprague-Dawley-descended rats obtained from our own breeding colony. Body weight ranges were $274-434 \mathrm{~g}$ for males and 193$300 \mathrm{~g}$ for females. The subjects were randomly assigned to one of four groups $(n \mathrm{~s}=12)$, counterbalanced within groups for sex. The animals were individually housed in standard hanging stainless steel wire-mesh cages in a vivarium maintained on a 16:8-h light:dark cycle. Experimental manipulations occurred near the middle portion of the light phase. The animals received free access to Purina Lab Chow, whereas water availability was limited to 30 min per day following a progressive deprivation schedule initiated 1 week prior to the start of the study. From the time of weaning until the start of the study, all the animals were handled for $30 \mathrm{sec}$, three times per week.

\section{Apparatus}

Six identical copies of each of two different types of experimental chambers were used. Chamber V was a $27-\mathrm{cm}$-long box in a truncated-V shape $(29.5 \mathrm{~cm}$ in height, $21.5 \mathrm{~cm}$ wide at the top, and $5.5 \mathrm{~cm}$ wide at the bottom). The floor was made up of two $27-\mathrm{cm}-$ long plates, $2 \mathrm{~cm}$ wide, with a $1.5-\mathrm{cm}$ gap between the two plates. A $0.7-\mathrm{mA}, 0.5$-sec constant-current footshock, produced by a highvoltage AC circuit in series with a $1.0-\mathrm{M} \Omega$ resistor, could be deliv- ered through the metal walls and floor of the chamber. The ceiling was clear Plexiglas, the front and back walls were black Plexiglas, and the side walls were stainless steel. Each of six copies of Chamber $\mathrm{V}$ was housed in a separate sound- and light-attenuating environmental isolation chest. The chamber was illuminated by a $7-\mathrm{W}$ (nominal at $120 \mathrm{VAC}$, but driven at $50 \mathrm{VAC}$ ) light bulb, which was mounted on the inside wall of the environmental enclosure, approximately $30 \mathrm{~cm}$ from the center of the experimental chamber. The light entered the chamber primarily by reflection from the ceiling of the environmental chest.

Chamber R was rectangular, measuring $24.0 \times 9.0 \times 12.5 \mathrm{~cm}$ $(1 \times w \times h)$. The walls and ceiling of Chamber $R$ were clear Plexiglas, and the floor consisted of stainless steel rods measuring $0.5 \mathrm{~cm}$ in diameter, spaced $1.5 \mathrm{~cm}$ apart (center to center). The rods were connected via NE-2 bulbs, which allowed for the delivery of the constant-current footshock. Each of six copies of Chamber R was housed in separate light- and sound-attenuating environmental isolation chambers. Each chamber was dimly illuminated by a 2-W (nominal at $120 \mathrm{VAC}$, but driven at $50 \mathrm{VAC}$ ) incandescent houselight mounted on an inside wall of the environmental chest located approximately $30 \mathrm{~cm}$ from the animal enclosure. The light intensities inside the two types of chambers were approximately equal, due to the difference in opaqueness of the walls of Chambers $\mathrm{V}$ and $\mathrm{R}$.

All the chambers ( $V$ and $R$ ) could be equipped with a water-filled lick tube that extended $1 \mathrm{~cm}$ into a cylindrical niche, which was $4.5 \mathrm{~cm}$ in diameter, left-right centered, with its bottom $1.75 \mathrm{~cm}$ above the floor of the apparatus and $5.0 \mathrm{~cm}$ deep. There was a photobeam detector $1 \mathrm{~cm}$ in front of the lick tube that was broken whenever the subject licked the tube. Three $45-\Omega$ speakers on the inside walls of the isolation chests could deliver either a low-frequency complex tone $(500$ and $570 \mathrm{~Hz})$, a white noise, or a click $(6 \mathrm{~Hz})$. All the auditory stimuli were presented at $6 \mathrm{~dB}$ above a constant $76-\mathrm{dB}$ background noise provided by ventilation fans. All auditory cues were measured on the $\mathrm{C}$ scale. A visual stimulus that consisted of a flashing light $(0.25 \mathrm{sec}$ on $/ 0.25 \mathrm{sec}$ off $)$ could be presented. The light was provided by either a $25-\mathrm{W}$ bulb (Chamber $\mathrm{R}$ ) or a $100-\mathrm{W}$ bulb (Chamber V), both nominal at 120 VAC, but driven at 80 VAC. The bulbs were mounted on an inside wall of the environmental chest, approximately $30 \mathrm{~cm}$ from the center of the experimental chamber. When presented, the flashing light served as CS A. The white noise and low-frequency complex tone served as CSs B and C, counterbalanced within groups. The clicks served as CS X. All stimuli were $10 \mathrm{sec}$ in duration except for the US, which was $0.5 \mathrm{sec}$ in duration. The physical identity of Contexts 1 and 2 was counterbalanced between Chambers R and V within groups.

\section{Procedure}

Acclimation. On Days 1 and 2, all the subjects received daily 60-min acclimation sessions in Context 1 with the lick tubes present. On Day 1, no stimuli were presented. On Day 2, all cues (A, B, C, and $\mathrm{X}$ ) were programmed to occur twice for $10 \mathrm{sec}$ each in order to minimize later configuring of the cues when they were presented in compound. Trial order was tone, flashing light, clicks, noise, clicks,

Table 1

Design of Experiment 1

\begin{tabular}{lcccc}
\hline Group & Phase $1^{2}$ & Phase $2^{2}$ & \multicolumn{1}{c}{ Phase $3^{2}$} & Test $^{1}$ \\
\hline Inhib & $48 \mathrm{~A}+/ 84 \mathrm{AB}-$ & $12 \mathrm{X}+$ & $36 \mathrm{BX}-/ 12 \mathrm{~B}-/ 12 \mathrm{X}-$ & $\mathrm{X}$ \\
Neutral & $48 \mathrm{~A}+/ 84 \mathrm{AB}-$ & $12 \mathrm{X}+$ & $36 \mathrm{CX}-/ 12 \mathrm{~B}-/ 12 \mathrm{X}-$ & $\mathrm{X}$ \\
NoExt & $48 \mathrm{~A}+/ 84 \mathrm{AB}-$ & $12 \mathrm{X}+$ & $60 \mathrm{~B}-$ & $\mathrm{X}$ \\
Ext & $48 \mathrm{~A}+/ 84 \mathrm{AB}-$ & $12 \mathrm{X}+$ & $48 \mathrm{X}-/ 12 \mathrm{~B}-$ & $\mathrm{X}$ \\
\hline
\end{tabular}

Note-CS A was a flashing light; CSs B and C were white noise and a highfrequency complex tone, counterbalanced within groups; CS X was a click train. "+" denotes reinforcement with a footshock. "-" denotes no reinforcement. Superscripts indicate context. Numbers preceding letters indicate the total number of trials in that phase. 
flashing light, noise, and tone for all the subjects. Mean intertrial interval (ITI) was $7.5 \mathrm{~min}$ (range: $6-9 \mathrm{~min}$; all reported ITIs were measured from CS onset to CS onset, including time from the beginning of the session to the end of the session). There were no presentations of the US during this phase. The subjects had free access to the water-filled lick tubes.

Phase 1. On Days 3-8, all the subjects received daily 120-min conditioned inhibition training sessions in Context 2. The subjects received 8 daily reinforced presentations of A randomly interspersed with 14 daily nonreinforced compound presentations of $\mathrm{AB}$. The mean ITI was $5.45 \mathrm{~min}$ (range: $2-9 \mathrm{~min}$ ). On reinforced trials, the CS and US coterminated. For this phase and all subsequent phases until reacclimation, the lick tubes were removed from the experimental chambers

Phase 2. On Days 9 and 10, all the subjects received daily 90min conditioning sessions in Context 2 . All the subjects received six daily reinforced presentations of X. The CS and US coterminated. The mean ITI was $15 \mathrm{~min}$ (range: 13-21 $\mathrm{min}$ ).

Phase 3. On Days 11 and 12, the subjects received daily 60-min extinction sessions conducted in Context 2. The subjects in Group Inhib received 18 daily nonreinforced presentations of $\mathrm{B}$ and $\mathrm{X}$ compounded together, 6 daily nonreinforced presentations of $\mathrm{B}$, and 6 daily nonreinforced presentations of X. The subjects in Group Neutral received 18 daily nonreinforced presentations of $\mathrm{C}$ and $\mathrm{X}$ compounded together, 6 daily nonreinforced presentations of $\mathrm{B}$, and 6 daily nonreinforced presentations of $X$. The subjects in Group NoExt received 30 daily nonreinforced presentations of $B$ alone. The subjects in Group Ext received 24 daily nonreinforced presentations of $\mathrm{X}$ and 6 daily nonreinforced presentations of B. For all groups, the first CS onset occurred $2 \mathrm{~min}$ into the session, and the last CS onset occurred $59 \mathrm{~min}$ into the session. Mean ITI was 2 min (range: 1-4 min). The interspersed elemental presentations of $X$ and $B$ were included to help reduce configuring in Groups Inhib and Neutral. A similar technique was used by Rescorla (2000; see also Rescorla, 2006 , for another example) in which he suggested that some elemental exposure to the target during extinction (and pretraining exposure to all cues as we did during acclimation) could help reduce configuring and, consequently, reduce generalization decrement between extinction treatment and test.

Reacclimation. On Days 13 and 14, all the subjects were reacclimated to Context 1 during a daily 60 -min session. The subjects had free access to the water-filled lick tubes, and no nominal stimuli were programmed to occur. The purpose of these sessions was to reestablish a stable rate of drinking behavior (which might have been differentially disrupted by the footshock US), thereby providing similar baseline behavior across the four groups upon which conditioned lick suppression was to be assessed.

Testing on X. On Day 15, all the subjects were tested for conditioned lick suppression to X in Context 1. Upon placement in the test chamber, time spent drinking by each subject was recorded. Immediately after completion of an initial 5 cumulative seconds of licking in the absence of any nominal stimulus (the pre-CS score), the subjects were presented with X. Thus, all the subjects were drinking at the time of CS onset. Time to complete an additional 5 cumulative seconds of licking in the presence of $\mathrm{X}$ was recorded. The times recorded during the presentation of $\mathrm{X}$ were interpreted as reflecting the subjects' expectancy of the US following onset of X. The test session was $16 \mathrm{~min}$ in duration, and a ceiling score of $15 \mathrm{~min}$ was imposed on the time to complete 5 cumulative seconds of drinking in the presence of $X$.

All test scores were converted to $\log _{10}$ to better approximate the within-group normal distributions assumed by parametric statistical tests. Following the convention of our laboratory, all animals that took more than $60 \mathrm{sec}$ to complete their first 5 cumulative seconds of licking (i.e., prior to CS onset) during the test session were scheduled to be eliminated from the study, because such long latencies may be considered indicative of unusually great fear of the test context. In practice, no subjects in this experiment met the elimination criterion.

\section{Results and Discussion}

We observed the basic protection-from-extinction effect, as evidenced by stronger conditioned suppression in Group Inhib relative to Group Ext. More importantly, we observed a stronger protection effect when the extinction trials occurred in compound with a conditioned inhibitor compared with an associatively neutral stimulus (see Figure 3 ). The following analyses support these conclusions.

A one-way ANOVA was conducted on the pre-CS scores to assess baseline responding. There were no differences between groups $(p>.31)$. The mean pre-CS data for Groups Inhib, Neutral, NoExt, and Ext were 0.95, 1.10, 1.04, and 1.00, respectively. A similar ANOVA was conducted on the CS data. This ANOVA did detect a group difference $\left[F(3,44)=8.53, M S_{\mathrm{e}}=0.11, p<.01\right.$, Cohen's $f=$ 0.69; Myers \& Wells, 2003]. Planned comparisons were conducted to assess the source of this variance. Group Inhib suppressed more than did Group Neutral $[F(1,44)=$ $8.54, p<.01$ ], showing that a conditioned inhibitor was more effective in protecting the target cue from extinction than was a neutral stimulus. There was not a difference in conditioned suppression between Groups Inhib and NoExt $[F(1,44)=1.03, p>.10]$, suggesting that the protection provided by the conditioned inhibitor was complete, since suppression did not statistically differ from that for a group that did not receive extinction. Lastly, no difference was detected between Groups Neutral and $\operatorname{Ext}[F(1,44)=0.02$, $p>.10]$, suggesting that the neutral stimulus did not appreciably protect the target cue from extinction once we had attenuated generalization decrement.

These data show a protection-from-extinction effect provided by a conditioned inhibitor. Moreover, the protection afforded by a conditioned inhibitor was greater than that afforded by a neutral stimulus. These data support the prediction of the ECH (Denniston et al., 2001; Stout \& Miller, 2007) and traditional error correction models that a conditioned inhibitor more effectively protects a stimulus from extinction than does an associatively neutral stimulus. There was no difference in suppression to a target that was extinguished in compound with a neutral stimulus and one that was extinguished alone. That is, protection

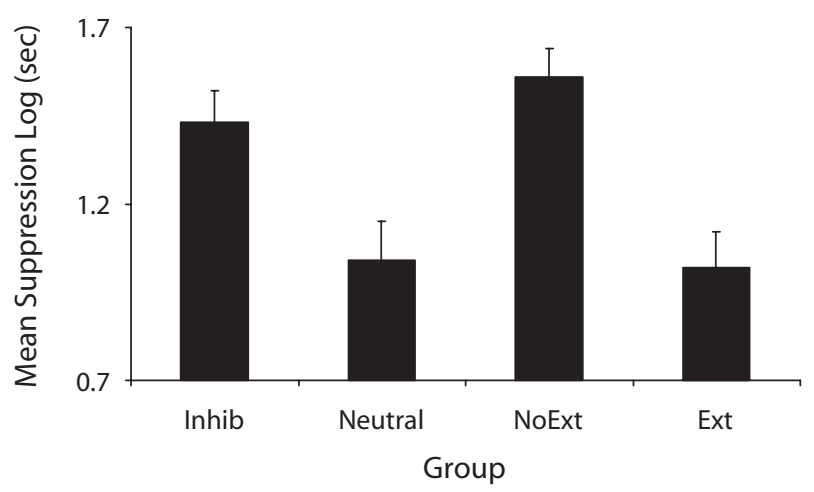

Figure 3. Experiment 1: Mean times (log sec) to complete 5 cumulative seconds of licking in the presence of the target cue. All the subjects were tested on $\mathrm{X}$ alone. 
due to generalization decrement was not observed. Presumably, this is because either generalization decrement was masked by floor level suppression in Groups Ext and Neutral or the protection effect provided by generalization decrement may have been counteracted by the $\mathrm{X}$ - trials. The latter account is consistent with the findings of Rescorla (2000), who reported that extinction of X in compound with a neutral stimulus intermixed with $\mathrm{X}$-alone trials resulted in responding that was comparable to extinguishing an excitor alone. The ECH correctly predicts that a conditioned inhibitor should provide more protection from extinction than should a neutral stimulus, but the model is not alone in making this prediction. Models of learning that assert that extinction depends on reduction of total error (e.g., Rescorla \& Wagner, 1972) also anticipate this pattern of results. They do so by assuming that during extinction, the negative and positive associative strengths, from B and X, respectively, should cancel each other out, thereby resulting in a net zero balance. Thus, there is not a discrepancy between the expected outcome and the actual absence of an outcome. In essence, the inhibitor causes subjects to expect no outcome; thus, outcome omission is not surprising. Consequently, no change is expected in X's associative strength, and $\mathrm{X}$ is expected to elicit excitatory responding when it is subsequently tested. Because there are competing accounts for the protection-from-extinction effect, Experiment 3 was conducted to differentiate between these models. Experiment 2 was conducted to set up Experiment 3.

\section{EXPERIMENT 2}

Experiment 2 replicated Experiment 1 in a sensory preconditioning preparation. This was done in anticipation of Experiment 3, in which we attempted to retroactively reduce X's protection from extinction provided by extinction treatment in the presence of a conditioned inhibitor (B) by extinguishing the excitor (A) that was used to train the inhibitor. Previous experiments have demonstrated that it is very difficult to decrease responding to a stimulus after it has already gained appreciable overt control over behavior without presenting that cue itself (such as in conventional extinction or overexpectation treatment) or devaluing the US (Denniston, Miller, \& Matute, 1996; Miller, Hallam, \& Grahame, 1990; Miller \& Matute, 1996; Oberling, Bristol, Matute, \& Miller, 2000). Thus, it was necessary to avoid making any of the stimuli biologically relevant until extinction of A had occurred. This was achieved by using an innocuous surrogate outcome instead of a biologically significant US during Phases 1 and 2. The design of Experiment 2 was exactly the same as that used in Experiment 1 , except that a surrogate outcome was used instead of a footshock during training, and an additional phase consisting of pairings of the surrogate outcome and footshock was added to make the surrogate outcome biologically significant so that it would motivate behavior (see Table 2 for the experimental design).

\section{Method}

\section{Subjects}

The subjects were 24 male and 24 female, experimentally naive Sprague-Dawley-descended rats obtained from our own breeding colony. Body weight ranges were 265-344 g for males and $174-235 \mathrm{~g}$ for females. The subjects were randomly assigned to one of four groups $(n \mathrm{~s}=12)$, counterbalanced within groups for sex. The animals were housed and maintained in the same manner as in Experiment 1.

\section{Apparatus}

The experimental chambers were the same as those in Experiment 1. The shock intensity was increased to $1.0 \mathrm{~mA}$ to compensate for the decreased responding usually observed in a sensory preconditioning design. The visual and auditory stimuli were the same as those in Experiment 1 . In addition, a SonAlert device mounted on each environment chest was able to deliver a $1900-\mathrm{Hz}$ signal at $6 \mathrm{~dB}$ above background. The 5 -sec SonAlert served as the surrogate outcome (O).

\section{Procedure}

Except where noted, all the procedures were the same as those in Experiment 1.

Acclimation. On Days 1 and 2, all the subjects received acclimation sessions in Context 1 just like those in Experiment 1.

Phase 1. On Days 3-8, all the subjects received daily 120-min conditioned inhibition training sessions in Context 2. The subjects received 8 daily presentations of $\mathrm{A}$, reinforced with a surrogate outcome $\mathrm{O}$, interspersed with 14 daily nonreinforced compound presentations of AB. The mean ITI was $5.45 \mathrm{~min}$ (range: 2-9 min). Different schedules of trials were used on even and odd days. On reinforced trials, the onset of the surrogate outcome immediately followed the termination of the CS.

Phase 2. On Days 9 and 10, all the subjects received daily 90-min conditioning sessions in Context 2 . All the subjects received six daily presentations of $X$ that were reinforced with the surrogate outcome. The mean ITI was $15 \mathrm{~min}$ (range: 13-21 $\mathrm{min}$ ).

Phase 3. On Days 11 and 12, the subjects received daily 60-min extinction sessions conducted in Context 2 just like those in Experiment 1 .

Phase 4. On Day 13, all the subjects were given a 120-min conditioning session in which the innocuous surrogate outcome was

Table 2

Design of Experiment 2

\begin{tabular}{lccccc}
\hline Group & \multicolumn{1}{c}{ Phase $1^{2}$} & Phase $2^{2}$ & Phase $3^{2}$ & Phase $4{ }^{1}$ & Test $^{1}$ \\
Inhib & $48 \mathrm{~A}-\mathrm{O} / 84 \mathrm{AB}-$ & $12 \mathrm{X}-\mathrm{O}$ & $36 \mathrm{BX}-/ 12 \mathrm{~B}-/ 12 \mathrm{X}-$ & $8 \mathrm{O}+$ & $\mathrm{X}$ \\
Neutral & $48 \mathrm{~A}-\mathrm{O} / 84 \mathrm{AB}-$ & $12 \mathrm{X}-\mathrm{O}$ & $36 \mathrm{CX}-/ 12 \mathrm{~B}-/ 12 \mathrm{X}-$ & $8 \mathrm{O}+$ & $\mathrm{X}$ \\
NoExt & $48 \mathrm{~A}-\mathrm{O} / 84 \mathrm{AB}-$ & $12 \mathrm{X}-\mathrm{O}$ & $60 \mathrm{~B}-$ & $8 \mathrm{O}+$ & $\mathrm{X}$ \\
Ext & $48 \mathrm{~A}-\mathrm{O} / 84 \mathrm{AB}-$ & $12 \mathrm{X}-\mathrm{O}$ & $48 \mathrm{X}-/ 12 \mathrm{~B}-$ & $8 \mathrm{O}+$ & $\mathrm{X}$ \\
\hline
\end{tabular}

Note-CS A was a flashing light; CSs B and C were white noise and a low-frequency complex tone, counterbalanced within groups; CS X was a click train; and stimulus O was a SonAlert. "+" denotes reinforcement with a footshock. "-" denotes no reinforcement. Superscripts indicate different contexts. Numbers preceding letters indicate the total number of trials in that phase. 
paired with the biologically significant US in Context 1 . All the subjects received eight $\mathrm{O}-\mathrm{US}$ trials; the $\mathrm{CS}$ and US coterminated. Mean ITI was $15 \mathrm{~min}$ (range: $10-24 \mathrm{~min}$ ).

Reacclimation and testing. In Context 1, on Days 14 and 15, all the subjects were reacclimated, and on Day 16, all the subjects were tested for conditioned lick suppression to $\mathrm{X}$ in the same way as in Experiment 1.

\section{Results and Discussion}

We successfully replicated the basic effects of Experiment 1 using a sensory preconditioning preparation. That is, we observed the protection-from-extinction effect as indicated by stronger suppression in Group Inhib relative to Group Ext and to Group Neutral (see Figure 4).

A one-way ANOVA of the pre-CS data showed significant differences by group $[F(3,44)=2.91, p=.04]$. The mean pre-CS scores for Groups Inhib, Neutral, Control, and Ext were 1.16, 0.98, 1.08, and 0.98, respectively. Consequently, an ANCOVA was performed on the test data that included the pre-CS scores as a covariate. This enabled us to parse out the effects of pre-CS behavior from the test data. The ANCOVA showed a significant difference between groups $\left[F(3,43)=16.29, M S_{e}=0.11, p<.05\right.$, Cohen's $f=0.56$; Myers \& Wells, 2003]. Critically, Group Inhib showed significantly stronger conditioned suppression than did Group Neutral $[F(1,43)=17.64, p<.05]$. Group Inhib also suppressed more than did Group Ext $[F(1,43)=31.41, p<$ $.05]$. There was not a significant difference between Groups Inhib and NoExt $[F(1,43)=2.73, p>.05]$. An ANOVA was also performed to ensure that our results were not simply an effect of using an ANCOVA. All of the effects and planned comparisons remained the same.

These data show that we can observe the protectionfrom-extinction effect in a sensory preconditioning design. Granted, this conclusion should be accepted with some caution, given the baseline differences. In the next experiment, we investigated whether we could attenuate this protection effect by extinguishing the excitor used in inhibition training (A; X's second-order comparator stimulus in the framework of the ECH). As has previously been stated, this necessitated the experiment's being conducted within a sensory preconditioning procedure.

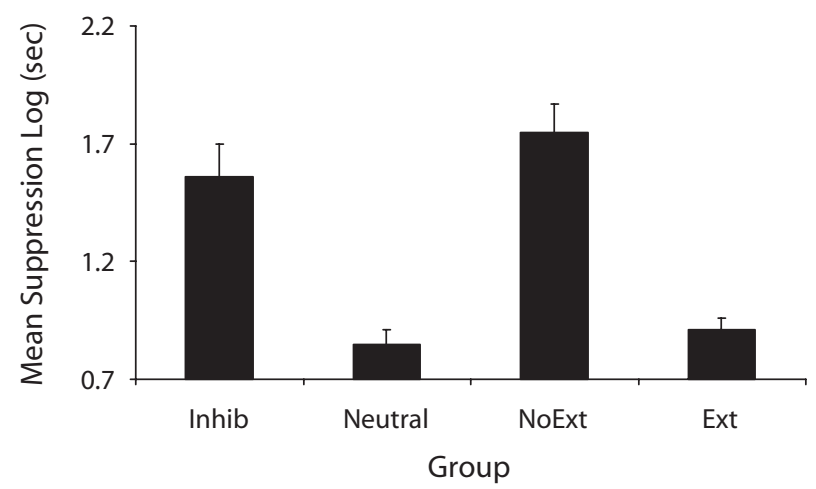

Figure 4. Experiment 2: Mean times (log sec) to complete 5 cumulative seconds of licking in the presence of the target cue. All the subjects were tested on $\mathrm{X}$ alone.

\section{EXPERIMENT 3}

In Experiment 3, all the subjects were given Pavlovian conditioned inhibition training in Phase 1 plus additional training of a separate excitor, D. In Phase 2, the target cue was conditioned. In Phase 3, all the subjects were extinguished to the target $\mathrm{X}$ in compound with the conditioned inhibitor, B. In Phase 4, the excitor (A) used to train the conditioned inhibitor was extinguished in Group InhibA, whereas the subjects in Group InhibD received nonreinforced presentations of irrelevant excitor D. According to the $\mathrm{ECH}$, conditioned suppression should be stronger in Group InhibD, relative to Group InhibA, due to the posttraining extinction of $\mathrm{A}$, which was expected to decrease responding to the target stimulus (see Table 3 for the experimental design).

Changes in behavioral control of a conditioned inhibitor due to posttraining extinction of the excitor used in inhibition training have been reported previously (e.g., Chang, Blaisdell, \& Miller, 2003; Hallam, Matzel, Sloat, \& Miller, 1990; Kaplan, 1985; Kaplan \& Hearst, 1985; Kasprow, Schachtman, \& Miller, 1987; Lysle \& Fowler, 1985; McConnell, Wheeler, Urcelay, \& Miller, 2009; Miller, Hallam, Hong, \& Dufore, 1991). These studies all showed that conditioned inhibition is reduced if the training excitor, the conditioned inhibitor's comparator stimulus, is extinguished (but see Rescorla \& Holland, 1977; Williams, Travis, \& Overmier, 1986). In the framework of the extended comparator hypothesis, we expected that this treatment would reduce conditioned suppression to the target stimulus in the present situation because the protection from extinction afforded by $\mathrm{B}$ is a performance-based effect that relies on B's inhibitory potential at the time of test. The model predicts that the negative output of Link 3 produced by B's inhibitory status will be weakened as a result of extinction of A. Because of the existence of a previously latent target-context association, extinction was expected to emerge. That is, less conditioned suppression was expected than would be observed in a control group that received extinction of $\mathrm{X}$ in compound with a conditioned inhibitor but was extinguished to an excitor other than the one used to produce the conditioned inhibitor. As was mentioned previously, this experiment necessitated being conducted in sensory preconditioning in order to avoid making the target CS biologically significant, which would mitigate against decreased behavioral control by the target cue (e.g., Miller \& Matute, 1996).

\section{Method}

\section{Subjects}

The subjects were 12 male and 12 female, experimentally naive Sprague-Dawley-descended rats obtained from our own breeding colony. Body weight ranges were 300-352 g for males and 205-250 g for females. The subjects were randomly assigned to one of two groups $(n \mathrm{~s}=12)$, counterbalanced within groups for sex.

\section{Apparatus}

The experimental chambers were the same as those used in Experiment 2. Given the large number of $\mathrm{O}$ presentations, the salience of $\mathrm{O}$ was increased from $6 \mathrm{~dB}$ above background to $8 \mathrm{~dB}$. In addition, a high-frequency tone $(1300 \mathrm{~Hz}, 6 \mathrm{~dB}$ above background) was pre- 
Table 3

Design of Experiment 3

\begin{tabular}{|c|c|c|c|c|c|c|}
\hline Group & Phase $1^{2}$ & Phase $2^{2}$ & Phase $3^{2}$ & Phase $4^{2}$ & Phase $5^{1}$ & Test $^{1}$ \\
\hline Inhib & 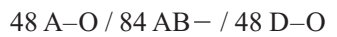 & $-\mathrm{O}$ & 2 & $198 \mathrm{~A}-$ & $8 \mathrm{O}+$ & $\mathrm{X}$ \\
\hline InhibD & $48 \mathrm{~A}-\mathrm{O} / 84 \mathrm{AB}-/ 48 \mathrm{D}-\mathrm{O}$ & $12 \mathrm{X}-\mathrm{O}$ & $36 \mathrm{BX}-/ 12 \mathrm{~B}-/ 12 \mathrm{X}-$ & $198 \mathrm{D}-$ & $8 \mathrm{O}+$ & $\mathrm{X}$ \\
\hline
\end{tabular}

Note-CSs A and D were a flashing light and a low-frequency complex tone, counterbalanced within groups; CSs B and $\mathrm{C}$ were a white noise and a click train; CS X was a high-frequency tone; and stimulus O was a buzzer. "+" denotes reinforcement with footshock. "-" denotes no reinforcement. Superscripts indicate different contexts. Numbers preceding letters indicate the total number of trials in that phase.

sented from the same speaker that delivered the low-frequency tone. The flashing light and low-frequency tone served as CSs A and D, counterbalanced within group. The white noise and clicks served as CS B, counterbalanced within group. The high-frequency tone served as CS X. The buzzer served as the surrogate outcome. All the stimuli were $10 \mathrm{sec}$ in duration, except for the surrogate outcome, which was $5 \mathrm{sec}$ in duration, and the US, which was $0.5 \mathrm{sec}$ in duration.

\section{Procedure}

Except where noted, all of the procedures were the same as those in Experiment 2.

Acclimation. On Days 1 and 2, all the subjects received daily 60-min acclimation sessions in Context 1 with the lick tubes present. On these days, all cues (A, B, D, and X) were programmed to occur a total of twice for $10 \mathrm{sec}$ each in order to minimize configuring and unconditioned suppression. Trial order was clicks, tone, light, tone, and noise. On Day 1, the high tone was presented; on Day 2, the low tone was presented. The mean ITI was $12 \mathrm{~min}$ (range: 7-17 min). There were no presentations of the US during this phase. The subjects had free access to the water-filled lick tubes.

Phase 1. On Days 3-8, all the subjects received Pavlovian conditioned inhibition training like that in Experiment 2, interspersed with eight daily presentations of $\mathrm{D}$ reinforced with the surrogate outcome. The mean ITI was $4 \mathrm{~min}$ (range: $1-6 \mathrm{~min}$ from CS onset to CS onset). Different schedules were used on even and odd days.

Phase 2. On Days 9 and 10, all the subjects received conditioning training like that in Experiment 2.

Phase 3. On Days 11 and 12, all the subjects received the same extinction treatment as Group Inhib in Experiment 2.

Phase 4. On Days 13 and 14, all the subjects were given daily 60min extinction sessions in Context 2. The subjects in Group InhibA were presented with 100 daily nonreinforced exposures to A. The subjects in Group InhibD received 100 daily extinction trials of D, an irrelevant excitor that was not associated with the conditioned inhibitor. The mean intertrial interval was 0.6 min (range: 0.25-1.75). No lick tubes were present.

Phase 5. On Day 15, all the subjects were given O-US pairings like those in Experiment 2.

Reacclimation. On Day 16 and 17, all the subjects were reacclimated to Context 1 in the same way as in Experiment 2.

Testing on $\mathbf{X}$. On Day 16, all the subjects were tested for conditioned lick suppression to $\mathrm{X}$ in Context 1 . Testing procedure took place in the same way as in Experiment 2. One subject was eliminated (from Group InhibA) due to failure to complete 5 cumulative seconds of licking within the first $60 \mathrm{sec}$ (i.e., prior to CS onset). This subject's data were excluded from all of the following data analyses.

\section{Results and Discussion}

Extinction of the excitor used to train the conditioned inhibitor attenuated responding to the target CS. Presumably, this treatment retroactively weakened the protection effect that was being driven by A. There were no significant pre-CS group differences $(p>.10$; mean pre-CS scores for Groups Inhib A and Inhib D were 1.18 and 1.25 , respectively). An ANOVA conducted on the CS test data showed a significant difference between the two groups $[F(1,21)=26.97, p<.01]$, showing that the subjects in Group InhibA responded less than did the subjects in Group InhibD, as was predicted by the ECH (mean suppression was 1.01 and $1.62 \log \mathrm{sec}$, respectively).

The ECH is unique in being able to account for the waning of responding to the target stimulus after $\mathrm{A}$ was extinguished. In the framework of the $\mathrm{ECH}$, responding to the target was attenuated because it no longer was being augmented by the negative output from the secondorder comparator process produced by A's association with the US.

\section{GENERAL DISCUSSION}

In Experiments 1 and 2, we demonstrated that a conditioned inhibitor is more effective in protecting a target CS from extinction than is an associatively neutral stimulus. In Experiment 3, we found that this heightened protection effect can be attenuated by extinguishing the excitor used to train the conditioned inhibitor. We acknowledge that the attenuation of the protection effect was demonstrated only when a surrogate outcome was used. Although the ECH does predict that this effect should also be observed in first-order conditioning, this was not explicitly demonstrated in this set of experiments (refer back to the introduction of Experiment 2 for an explanation of why some retrospective revaluation effects are difficult to demonstrate in first-order conditioning). Also, it should be noted that all of the effects were observed after interspersed elemental and compound extinction trials. This method of training was used to reduce configural processes, which is one way that a companion conditioned inhibitor can provide a target with protection from extinction, but our goal in this series was to assess the effects of protection provided by a companion stimulus owing to its inhibitory properties. Thus, we intentionally tried to minimize generalization decrement. Although we did not test the putative inhibitor B for conditioned inhibition, we based our parameters on those of a previous study (Friedman et al., 1998) that explicitly confirmed that these procedures produced an inhibitory relationship between B and the outcome, as demonstrated by negative summation and retardation tests. Thus, it appears reasonable to assume that our inhibition training also produced a conditioned inhibitor. Moreover, the control conditions confirmed the specificity of the protection effect to extinction in the presence 
of an inhibitor and the recovery of extinction effect to the conditioned excitor that was used in inhibition training.

The ECH (Denniston et al., 2001; Stout \& Miller, 2007) accounts for these effects as being the result of secondorder comparator processes interacting with first-order comparator processes. In this framework, in Experiments 1 and 2, Group Inhib formed an association between the target CS, X, and the outcome (Link 1) during Phase 2 of conditioning (in Experiment 2, a surrogate US [O] was used during training, and this was later paired with the biologically significant US). X formed a strong association with the conditioned inhibitor, B (Link 2), with which it was paired during extinction treatment in Phase 3. Although $\mathrm{B}$ did not have a direct association with the outcome (Link 3), it did activate an outcome representation indirectly through its association with $\mathrm{A}$, the conditioned excitor used to train the inhibitor (Links 3.2 and 3.3). A did not serve as a first-order comparator stimulus for $\mathrm{X}$, because there was no direct association between $\mathrm{A}$ and $\mathrm{X}$. This made A a pure second-order comparator for X. The second-order comparator process produced a negative output for Link 3, which was then compared with the strength of Link 1, resulting in strong conditioned suppression to the target CS. In Group Neutral, Links 1, 2, and 3 were established just as in Group Inhib, but the neutral stimulus (C) did not have an association with any stimulus other than the context (and of course, the target), and the context was presumably far less excitatory than was A. Thus, less conditioned suppression to the target stimulus was expected in this group because it did not receive the added benefit of negative output to augment responding. In Group Ext, the context was expected to become a strong effective comparator stimulus to X (Link 2) because no other stimulus was present to overshadow the $\mathrm{X}$ context association. Hence, weak responding to the target was expected in part as a result of the context activating an outcome representation better (through Link 3, which was formed during acquisition), thereby making the indirectly activated US representation strong, or at least comparable to the US representation directly activated by the target. And lastly, strong responding was predicted in Group NoExt, which did not receive any extinction treatment.

It is possible that generalization decrement may have played a role in producing the protection-from-extinction effect observed in Group Inhib, but this is unlikely given that generalization decrement was not observed in Group Neutral (as compared with Group Ext). Moreover, we took extra measures to reduce generalization decrement by giving $\mathrm{X}$-alone trials during extinction. The elemental presentations of $X$ are a technique used by other researchers, including Rescorla (2000, 2006), who showed that elemental extinction does extinguish responding to a degree, but subsequent compound extinction with an additional excitor further extinguished responding, relative to additional elemental extinction presentations. Therefore, we can assume that our observation of differential responding as a function of the presence or absence of a conditioned inhibitor was due to the compound extinction trials that influenced responding, in addition to the effect of the elemental presentations. Specifically, the differential responding was apparently a result of the different associative strengths of the compound stimuli, which produced an effect above and beyond that of generalization decrement.

The ECH accounts for the results of Experiment 3 because it assumes that the comparator process takes into consideration the current associative value of all stimuli associated with the target CS. Extinguishing A following the compound extinction treatment presumably undermined the inhibitory potential of $\mathrm{B}$, thereby eliminating the negative output of Link 3 , which was what drove the higher conditioned suppression to $\mathrm{X}$ in Group Inhib in Experiments 1 and 2. In essence, extinguishing A made Group Inhib comparable to Group Neutral. Notably, according to the $\mathrm{ECH}$, the difference between Groups Inhib and Neutral in Experiments 1 and 2 and between Groups InhibA and InhibD in Experiment 3 is contingent upon the effective Link 3 having a negative output at the time of testing. In the ECH, as in the original comparator hypothesis (Miller \& Matzel, 1988), all associations are positive (or null), but outputs of comparator processes can take a negative value.

As was mentioned before, total error reduction accounts of extinction can explain the results of Experiment 1 as well as the ECH. They assume that extinction is based on an error correction rule in which (inhibitory) learning occurs whenever the subject is surprised by the outcome and must therefore make adjustments (i.e., learning) in order to more accurately predict the outcome on the next trial. In the present experiments, these models assume that B should acquire negative (i.e., inhibitory) associative strength, which should cancel out X's positive (i.e., excitatory) associative strength, thereby resulting in a zero net outcome expectation. During extinction, no US is predicted to occur, which results in no change in X's associative strength (i.e., no extinction). Thus, when $\mathrm{X}$ is presented alone at test, it should still have considerable excitatory strength. These models also predict partial protection provided by a neutral stimulus. During extinction, the subject should expect the outcome to occur on the basis of X's positive associative strength. When the US is not presented, inhibition is expected to develop. But the decrease in associative strength should be distributed between $\mathrm{X}$ and the neutral stimulus, $\mathrm{C}$, thereby limiting the decrease in associative strength of $\mathrm{X}$ during extinction treatment. Of course, in Group Ext, which was extinguished to $\mathrm{X}$ elementally, these models would predict that $\mathrm{X}$ should undergo the maximal decrease in associative strength during extinction, resulting in very weak responding to $\mathrm{X}$ at test. Thus, both the $\mathrm{ECH}$ and total error reduction models predict stronger protection from extinction provided by a conditioned inhibitor relative to a neutral stimulus, which was observed.

However, only the ECH can account for the results in Experiment 3. It does so by assuming that extinction of $\mathrm{A}$, the excitor used to train the conditioned inhibitor, eliminated the negative output that was otherwise produced by the second-order comparator process. Thus, 
there was nothing to augment responding to $\mathrm{X}$ based on Link 1 alone, and accordingly, conditioned suppression to $\mathrm{X}$ should decrease. That is, with extinction of A, Group InhibA in Experiment 3 should perform like Group Neutral in Experiments 1 and 2, which is what was observed. Traditional total error reduction models cannot account for situations of retrospective revaluation in which responding to the target CS changes as a function of posttraining manipulations of an associated cue in the absence of the target cue. However, Van Hamme and Wasserman's (1994) revision of the Rescorla-Wagner (1972) model allows the parameter for the target cue $(\alpha)$ to assume a negative value when it is absent, provided that an associate of the target is present. This modification allows the model to account for retrospective revaluation, such as the attenuation of conditioned inhibition as a result of extinction of the excitor used in inhibition training. However, the revised version is no better than the original Rescorla-Wagner model (or other total error reduction models) in explaining the results of Experiment 3, because CSs A and X were never paired; hence, the revised Rescorla-Wagner model predicts no effect of extinguishing A on responding to X. Dickinson and Burke (1996) provided another acquisition-focused account of retrospective revaluation. But this model, like Van Hamme and Wasserman's model, anticipates only retrospective revaluation of stimuli that have direct associations to the stimulus that get revalued. Hence, it too does not account for the recovery of extinction effect observed in Experiment 3. Admittedly, this shortcoming of these acquisition-focused models was also present in the original comparator hypothesis (Miller \& Matzel, 1988). It is possible that future versions of acquisition-focused models may be created that will expand the explanatory power of these models to account for such phenomena, as was done with the extended comparator hypothesis (Denniston et al., 2001). Moreover, although the ECH is the only formal model that can currently account for all of the findings of these experiments, it is not unreasonable that other models that include similar retroactive competition processes may also be able to account for these effects. That is, the mechanisms the ECH uses to account for these effects may be applicable to a general class of theories that rely on retrieval processes. Other possible alternative explanations include generalization decrement or contextspecific training. However, these are not likely, because generalization decrement was shown to play a minimal role in our experiments, as evidenced by equal responding in Group Neutral and Group Ext, and all groups received training in Context 2 and testing in Context 1. Therefore, any context effects that may have occurred should have been equated across groups.

The present experiments emphasize the role that second-order comparator processes play in determining the response potential of a target cue. That is, stimuli that are not directly associated with the target CS can still influence responding to it. This is consistent with a number of other demonstrations in which a target's behavioral control is affected by second-order comparators (e.g., McConnell et al., 2009; Urushihara, Wheeler, Pineño, \& Miller,
2005; Witnauer \& Miller, 2007). For example, McConnell et al. demonstrated protection from latent inhibition and attenuation of this protection effect after extinction of a second-order comparator stimulus. Similarly, Urushihara et al. demonstrated superconditioning (Rescorla, 1971) and then attenuation of the superconditioning effect after extinction of a second-order comparator stimulus. Moreover, several demonstrations of counteraction effects have highlighted the role of second-order comparator processes in determining the response potential of the target cue following the combination of two response-degrading treatments (e.g., Blaisdell, Bristol, Gunther, \& Miller, 1998). The take-home message of the present experiments is that stimuli that are only indirectly associated with the target stimulus can still play a large role in determining the response potential of the target cue via higher order comparator processes. Furthermore, these experiments emphasize that information processing and competition between stimuli for behavioral expression at the time of testing play an important role in determining conditioned responding. These data are also inconsistent with the view that unfulfilled outcome expectations based on all cues present are the driving force of extinction (e.g., Bouton, 2004). Seemingly, conditioned inhibitors reduce extinction not through their impact on outcome expectation, but through their being associated with an excitor.

\section{AUTHOR NOTE}

NIMH Grant 33881 provided support for this research. We thank Joseph Alessandro, Eric Curtis, Jeremie Jozefoviez, Mario Laborda, Gonzalo Miguez, Cody Polack, Sarah Sterling, Yumu Tanaka, and James Witnauer for comments on an earlier version of the manuscript. Correspondence concerning this article should be addressed to R. R. Miller, Department of Psychology, SUNY, Binghamton, NY 13902-6000 (e-mail: rmiller@binghamton.edu).

\section{REFERENCES}

Blaisdell, A. P., Bristol, A. S., Gunther, L. M., \& Miller, R. R. (1998). Overshadowing and latent inhibition counteract each other: Support for the comparator hypothesis. Journal of Experimental Psychology: Animal Behavior Processes, 24, 335-351.

Bouton, M. E. (2004). Context and behavioral processes in extinction. Learning \& Memory, 11, 485-494.

Chang, R. C., Blaisdell, A. P., \& Miller, R. R. (2003). Backward conditioning: Mediation by the context. Journal of Experimental Psychology: Animal Behavior Processes, 29, 171-183.

Denniston, J. C., Miller, R. R., \& Matute, H. (1996). Biological significance as a determinant of cue competition. Psychological Science, 7, 325-331.

Denniston, J. C., Savastano, H. I., \& Miller, R. R. (2001). The extended comparator hypothesis: Learning by contiguity, responding by relative strength. In R. R. Mowrer \& S. B. Klein (Eds.), Handbook of contemporary learning theories (pp. 65-117). Mahwah, NJ: Erlbaum.

Dickinson, A., \& Burke, J. (1996). Within-compound associations mediate the retrospective revaluation of causality judgments. Quarterly Journal of Experimental Psychology, 49B, 60-80.

Friedman, B. X., Blaisdell, A. P., Escobar, M., \& Miller, R. R. (1998). Comparator mechanisms and conditioned inhibition: Conditioned stimulus preexposure disrupts Pavlovian conditioned inhibition but not explicitly unpaired inhibition. Journal of Experimental Psychology: Animal Behavior Processes, 24, 453-466.

Hallam, S. C.,' Matzel, L. D., Sloat, J. S., \& Miller, R. R. (1990). Excitation and inhibition as a function of posttraining extinction of the excitatory cue used in Pavlovian inhibition training. Learning $\&$ Motivation, 21, 59-84. 
KaPlan, P. S. (1985). Explaining the effects of relative time in trace conditioning: A preliminary test of a comparator hypothesis. Animal Learning \& Behavior, 13, 233-238.

KaPlan, P. S., \& Hearst, E. (1985). Contextual control and excitatory versus inhibitory learning: Studies of extinction, reinstatement, and interference. In P. D. Balsam \& A. Tomie (Eds.), Context and learning (pp. 195-224). Hillsdale, NJ: Erlbaum.

Kasprow, W. J., Schachtman, T. R., \& Miller, R. R. (1987). The comparator hypothesis of conditioned response generation: Manifest conditioned excitation and inhibition as a function of relative excitatory strengths of CS and conditioning context at the time of testing. Journal of Experimental Psychology: Animal Behavior Processes, 13, 395-406.

Laborda, M. L., Witnauer, J. E., \& Miller, R. R. (2009). Contrasting $A A C$ and $A B C$ renewal: The role of context association. Manuscript submitted for publication.

Larrauri, J. A., \& Schmajuk, N. A. (2008). Attentional, associative, and configural mechanisms in extinction. Psychological Review, 115, 640-676.

Lovibond, P. F., Davis, N. R., \& O'Flaherty, A. S. (2000). Protection from extinction in human fear conditioning. Behavior Research \& Therapy, 38, 967-983.

LysLe, D. T., \& Fowler, H. (1985). Inhibition as a "slave" process: Deactivation of conditioned inhibition through extinction of conditioned excitation. Journal of Experimental Psychology: Animal Behavior Processes, 11, 71-94.

Mackintosh, N. J. (1975). A theory of attention: Variations in the associability of stimuli with reinforcement. Psychological Review, 82, 276-298.

McConnell, B. L., Wheeler, D. S., Urcelay, G. P., \& Miller, R. R. (2009). Protection from latent inhibition provided by a conditioned inhibitor. Journal of Experimental Psychology: Animal Behavior Processes, 35, 498-508.

Miller, R. R., Hallam, S. C., \& Grahame, N. J. (1990). Inflation of comparator stimuli following CS training. Animal Learning \& Behavior, 18, 434-443.

Miller, R. R., Hallam, S. C., Hong, J. Y., \& Dufore, D. S. (1991). Associative structure of differential inhibition: Implications for models of conditioned inhibition. Journal of Experimental Psychology: Animal Behavior Processes, 17, 141-150.

Miller, R. R., \& Matute, H. (1996). Biological significance in forward and backward blocking: Resolution of a discrepancy between animal conditioning and human causal judgment. Journal of Experimental Psychology: General, 125, 370-386.

MilLER, R. R., \& MATZEL, L. D. (1988). The comparator hypothesis: A response rule for the expression of associations. In G. H. Bower (Ed.), The psychology of learning and motivation (Vol. 22, pp. 51-92). New York: Academic Press.

Myers, J. M., \& Wells, A. D. (2003). Research design and statistical analysis (2nd ed.). Mahwah, NJ: Erlbaum.

Oberling, P., Bristol, A. S., Matute, H., \& Miller, R. R. (2000). Biological significance attenuates overshadowing, relative validity, and degraded contingency effects. Animal Learning \& Behavior, 28, 172-186.

PaVlov, I. P. (1927). Conditioned reflexes. London: Oxford University Press, Clarendon Press.

Pearce, J. M., \& Wilson, P. N. (1991). Effects of extinction with a compound conditioned stimulus. Journal of Experimental Psychology: Animal Behavior Processes, 17, 151-162.
Pineño, O. (2007). Protection from extinction by concurrent presentation of an excitor or an extensively extinguished CS. Psicológica, 28, 151-166.

RESCORLA, R. A. (1971). Variation in the effectiveness of reinforcement and nonreinforcement following prior inhibitory conditioning. Learning \& Motivation, 2, 113-123.

Rescorla, R. A. (2000). Extinction can be enhanced by a concurrent excitor. Journal of Experimental Psychology: Animal Behavior Processes, 26, 251-260.

Rescorla, R. A. (2003). Protection from extinction. Learning \& Behavior, 31, 124-132.

RESCORLA, R. A. (2006). Deepened extinction from compound stimulus presentation. Journal of Experimental Psychology: Animal Behavior Processes, 32, 135-144.

Rescorla, R. A., \& Holland, P. C. (1977). Associations in Pavlovian conditioned inhibition. Learning \& Motivation, 8, 429-447.

Rescorla, R. A., \& WAGNer, A. R. (1972). A theory of Pavlovian conditioning: Variations in the effectiveness of reinforcement and nonreinforcement. In A. Black \& W. F. Prokasy (Eds.), Classical conditioning II (pp. 64-99). New York: Appleton-Century-Crofts.

Soltysik, S. S., Wolfe, G. E., Nicholas, T., Wilson, W. J., \& GarciaSANCHEZ, J. L. (1983). Blocking of inhibitory conditioning within a serial conditioned stimulus-conditioned inhibitor compound: Maintenance of acquired behavior without an unconditioned stimulus. Learning \& Motivation, 14, 1-29.

Stout, S. C., \& Miller, R. R. (2007). Sometimes-competing retrieval (SOCR): A formalization of the comparator hypothesis. Psychological Review, 114, 759-783.

Thomas, B. L., \& Ayres, J. J. B. (2004). Use of the ABA fear renewal paradigm to assess the effects of extinction with co-present fear inhibitors or excitors: Implications for theories of extinction and for treating human fears and phobias. Learning \& Motivation, 35, 22-52.

Urcelay, G. P., Lipatova, O., \& Miller, R. R. (2009). Constraints on enhanced extinction resulting from extinction treatment in the presence of an added excitor. Learning \& Motivation, 40, 343-363.

Urushihara, K., Wheeler, D. S., Pineño, O., \& Miller, R. R. (2005). An extended comparator account of superconditioning. Journal of Experimental Psychology: Animal Behavior Processes, 31, 184-198.

Van Hamme, L. J., \& Wasserman, E. A. (1994). Cue competition in causality judgment: The role of nonrepresentation of compound stimulus elements. Learning \& Motivation, 25, 127-151.

WAGNER, A. R. (1981). SOP: A model of automatic memory processing in animal behavior. In N. E. Spear \& R. R. Miller (Eds.), Information processing in animals: Memory mechanisms (pp. 5-47). Hillsdale, NJ: Erlbaum.

Williams, D. A., Travis, G. M., \& Overmier, J. B. (1986). Withincompound associations modulate the relative effectiveness of differential and Pavlovian conditioned inhibition procedures. Journal of Experimental Psychology: Animal Behavior Processes, 12, 351-362.

Witnauer, J. E., \& Miller, R. R. (2007). Degraded contingency revisited: Posttraining extinction of a cover stimulus attenuates a target cue's behavioral control. Journal of Experimental Psychology: Animal Behavior Processes, 33, 440-450.

(Manuscript received June 9, 2009; revision accepted for publication August 25, 2009.) 